\title{
AÇÃO COLETIVA E DESENVOLVIMENTO LOCAL: O CASO DE POÇO VERDE
}

EduARDo de Lima CALDAS - elcaldas@hotmail.com

Escola de Artes, Ciências e Humanidades da Universidade de São Paulo, São Paulo - SP, Brasil

MARTIN JAYO - martin.jayo@usp.br

Escola de Artes, Ciências e Humanidades da Universidade de São Paulo, São Paulo - SP, Brasil

Estamos em meados de 1996, no chamado "polígono da seca" do Nordeste brasileiro. Mais especificamente em Poço Verde, um pequeno município do estado de Sergipe, distante 150 quilômetros da capital, Aracaju, fazendo divisa com o estado da Bahia.

O ano é de eleições municipais em todo o Brasil. Milton Santana, um médico de 39 anos, filiado ao PSC, está a apenas seis meses de concluir seu mandato como prefeito de Poço Verde. Ele não concorre à reeleição (mesmo porque, na época, ainda não existe essa possibilidade, que será instituída por emenda constitucional apenas no ano seguinte), e seu cargo é disputado por dois exprefeitos, José Everaldo de Oliveira (PMDB) e Carlos Alberto Lima (PSDB), que exerceram seus mandatos respectivamente em 1983-1987 e 1989-1992. Embora não dispute, por ora, nenhum cargo, Santana deseja encerrar seu mandato deixando uma boa impressão de sua passagem pela prefeitura. Quer ser lembrado como um prefeito realizador que deixou um legado positivo, o que será fundamental para projetos políticos futuros.

A área social é particularmente sensível na agenda de políticas públicas da região. Pobreza, desigualdade e exclusão são problemas que afligem o sertão há séculos, e a população de Poço Verde, infelizmente, está muito longe de desconhecê-los. São inúmeras as famílias do município que convivem com insuficiência crônica de trabalho e renda, de tempos em tempos chegando a ser ameaçadas pela fome. Em épocas difíceis, é comum que a palma (Opuntia cochenillifera, espécie de cacto abundante na região) se torne o único alimento disponível para seres humanos, cavalos e o parco rebanho de cabras e vacas.

Mas o segundo semestre de 1996 oferecerá, ao prefeito e a diferentes atores sociais e políticos do município, uma oportunidade ímpar para articular a busca de soluções para a situação. E isso se deve a uma conjunção de fatores: além de tratar-se de um ano eleitoral, o que por si estimula a discussão de políticas públicas para o município, também pesa o fato de, no âmbito federal, estar sendo criado um programa nacional com benefícios potenciais para o município. Trata-se do Programa Nacional de Fortalecimento da Agricultura Familiar (Pronaf), voltado a reduzir os níveis de pobreza no campo e promover a melhoria de renda e bem-estar dos agricultores familiares. 


\section{Pano de fundo: a economia de Poço Verde}

A população de Poço Verde, segundo dados da contagem populacional do Instituto Brasileiro de Geografia e Estatística (IBGE), era de 17.666 habitantes em $1996^{1}$, dos quais $44 \%$ residiam na zona urbana e 56\%, na rural. A agricultura e a pecuária eram (e continuam sendo até hoje) as atividades econômicas predominantes no município, com destaque para os cultivos de feijão, milho e mandioca e para a criação de gado de corte.

Essa produção, segundo dados do censo agropecuário 1996 do IBGE, provinha de um total de 2.490 estabelecimentos rurais. Desses, 1.755, ou 70,5\%, possuíam menos de 10 hectares, o que configura um largo predomínio de pequenas propriedades. Por outro lado, os 726 estabelecimentos com área entre 10 e 200 hectares, apesar de não chegarem a 30\% do total, representavam 70\% da área agrícola do município. Isso significa grande concentração de terra: apesar do grande número de propriedades pequenas, a maior parte da área está concentrada nas poucas propriedades maiores.

Outro dado importante é que, das cerca de 6.000 propriedades rurais e urbanas existentes no município, apenas 560 (menos de 10\%) são legalizadas em registro de cartório imobiliário. Além dos custos de deslocamento que precisariam ser incorridos, pelo fato de o cartório ser distante (não fica em Poço Verde, mas no município de Lagarto, que é a comarca jurisdicional e polo econômico regional), também influem nessa situação os custos burocráticos, muitas vezes proibitivos: despesas com taxas de registro, multas de atraso, obtenção de provas de propriedade, autenticações de documentos, honorários advocatícios etc.

Isso tinha um importante impacto na vida econômica do município em 1996. Ao não serem proprietários formais, os agricultores de Poço Verde não podiam hipotecar sua terra e, com isso, não dispunham das garantias exigidas pelo sistema financeiro em troca de empréstimos. Dessa forma, o seu acesso a crédito era impedido, seja para investimento (compra de máquinas, equipamentos e mesmo ferramentas, como pás e enxadas), seja para custeio da produção (compra de sementes, fertilizantes, defensivos e demais insumos da produção). Assim, embora houvesse terra disponível nas pequenas propriedades e mão de obra disposta a trabalhá-la, o aproveitamento desses fatores ficava comprometido pelo acesso restrito ao crédito.

Por fim, o município era servido por uma agência do Banco do Brasil, mas estava correndo o risco de perdê-la. O principal problema enfrentado pela agência era justamente não conseguir atingir as metas impostas pelo Banco para mantê-la operando. No que diz respeito especificamente a crédito, a meta era de 1.000 contratos emitidos e R \$ 1 milhão emprestados a cada ano. E a agência estava extremamente distante de atingi-la: não vinha conseguindo fechar mais do que 30 contratos de crédito por ano. O gerente da agência sabia que não havia muito a fazer para reverter o fechamento nessas circunstâncias e estava conformado, aguardando sua transferência pelo Banco para outra cidade, provavelmente em um novo cargo, inferior ao de gerente. Além disso, como o gerente era casado, o fechamento da agência significaria um deslocamento indesejado de toda a sua família.

Para o município de Poço Verde, a perda iminente de sua única agência bancária também não era uma perspectiva animadora. Era por meio dela que a prefeitura recebia, a cada 10 dias, o Fundo de Participação dos Municípios (FPM), pagava os seus fornecedores e servidores, enfim, administrava todas as suas operações financeiras. Para uma prefeitura municipal, uma agência bancária no município confere maior eficiência logística, além de certo prestígio, ou poder simbólico

\footnotetext{
${ }^{1}$ Em 2010, segundo o censo populacional do IBGE, a população havia crescido para 21.861 habitantes, mantendo-se relativamente inalterada a proporção urbano/rural.
} 
regional. Além disso, para os habitantes e o comércio, a agência significava o acesso a serviços básicos como recebimento e saques de aposentadorias, pensões e salários, pagamentos de contas etc. sem ter de se deslocar a um polo urbano maior, o que acabava incentivando a circulação local da renda e aumentando seus efeitos multiplicadores no município. "Vai ser triste se o Banco for embora por causa da situação econômica aqui em Poço Verde", refletia o prefeito Milton Santana, por volta de junho. E complementava: "Ainda mais se acontecer logo agora, no final do meu mandato...".

\section{Um fato novo: o lançamento do Pronaf}

Em meio a esse panorama, surgiu uma novidade: o lançamento do Pronaf, instituído pelo governo federal por meio do Decreto Presidencial n ${ }^{\circ} 1.946$, de 28 de junho de $1996 .{ }^{2}$ O programa passaria a oferecer créditos a municípios e a agricultores, com a finalidade de "promover o desenvolvimento sustentável do segmento rural constituído pelos agricultores familiares, de modo a propiciar-lhes o aumento da capacidade produtiva, a geração de empregos e a melhoria de renda" (artigo $1^{\circ}$ do Decreto $n^{\circ}$ 1.946). Para tanto, ele se constituía de quatro linhas básicas de atuação: (a) concessão de créditos (de até R $\$ 5$ mil para custeio e de até R\$ 15 mil para investimento) para agricultores familiares; (b) capacitação e profissionalização desses agricultores por meio de cursos e treinamentos; (c) financiamento de infraestrutura e serviços a municípios; e, finalmente, (d) financiamento de pesquisa e extensão rural, visando à geração e transferência de tecnologias para os agricultores familiares. E para a operacionalização do programa seriam usados, como agentes financeiros, bancos públicos, como o Banco do Brasil.

Junto com o lançamento do Programa, o Governo Federal também divulgava os critérios para enquadramento de produtores como beneficiários de créditos. Eram seis condições a serem atendidas:

1. Possuir, pelo menos, $80 \%$ da renda originária da agropecuária;

2. Explorar a atividade agropecuária em imóvel rural com área de até quatro módulos fiscais ${ }^{3}$;

3. Explorar a terra na condição de proprietário, parceiro, arrendatário ou posseiro;

4. Utilizar apenas mão de obra familiar ou manter, no máximo, dois empregados permanentes;

5. Residir na propriedade ou em aglomerado urbano próximo;

6. Possuir faturamento máximo anual de $\mathrm{R} \$ 27.500,00$ (em valores da época).

À primeira vista, na avaliação do prefeito, o Pronaf parecia cair como uma luva para as necessidades e carências dos agricultores de Poço Verde. A maioria dos produtores do município se encaixava nos seis critérios de enquadramento no Pronaf, e suas dificuldades para financiar a produção poderiam ser minoradas, com o acesso a uma linha crédito mais ajustada ao seu perfil. E, dado que o agente financeiro do Pronaf no município seria o Banco do Brasil, era possível até mesmo que, com os novos financiamentos que surgiriam, a cidade não perdesse a sua agência bancária. De quebra, ainda havia a possibilidade de o município se habilitar para receber empréstimos de longo prazo para a melhora de infraestrutura e serviços. Sem dúvida nenhuma, era um cenário mais alentador para terminar o mandato, comparativamente ao cenário do início do ano.

\footnotetext{
${ }^{2}$ A íntegra do Decreto está disponível em: http://www.planalto.gov.br/ccivil_03/decreto/D1946.htm. Acesso em 20.03.2012.

${ }^{3}$ Módulo fiscal é uma unidade de medida agrária empregada no Brasil desde a Lei no 6.746, de 1979. É expressa em hectares e varia de município para município, levando-se em conta o tipo de exploração predominante e a renda com ela obtida pelos produtores, entre outros fatores. A unidade serve de parâmetro para a classificação fundiária dos imóveis rurais, de acordo com a Lei ${ }^{\circ}$ 8.629, de 1993, classificando-se os imóveis rurais em minifúndio (área inferior a 1 módulo físcal), pequeno (de 1 a 4), médio (de 4 a 15) e grande (acima de 15). Em Poço Verde, o módulo físcal é de 4 hectares.
} 
Nem tudo, porém, era assim tão simples. Antes de liberar qualquer recurso, o Pronaf exigia que o município tivesse um Conselho Municipal de Desenvolvimento Rural (CMDR), um órgão paritário com participação de representantes da Prefeitura Municipal e da sociedade civil, responsável por elaborar um Plano Municipal de Desenvolvimento Rural. E, para concessão de créditos aos agricultores, exigia-se também que cada produtor tivesse um projeto aprovado pela Casa do Agricultor, ou pela empresa de extensão rural do estado com escritório no município, ou, ainda, pelo Sindicato de Trabalhadores Rurais. Tais exigências eram para garantir que as ações estivessem subordinadas a um planejamento local, que visasse a um desenvolvimento rural mais articulado em detrimento de um conjunto de ações pontuais, desfocadas e desarticuladas.

Poço Verde contava com as quatro instituições supracitadas - um CMDR, uma Casa do Agricultor, um escritório da Emdagro (empresa de extensão rural do estado de Sergipe) e um Sindicato de Trabalhadores Rurais ${ }^{4}$. Não havia, contudo, um Plano Municipal de Desenvolvimento Rural. Na avaliação do prefeito, seria necessário agir rápido e fazer com que todos esses atores passassem a trabalhar de forma articulada. O CMDR deveria elaborar e aprovar imediatamente um Plano Municipal de Desenvolvimento Rural, e, em seguida, seria necessário contar com os demais atores (Casa do Agricultor, Emdagro e Sindicato) a fim de assessorar os produtores e aprovar seus projetos individuais.

Um ponto especialmente nebuloso, ponderava o prefeito, eram as garantias a serem exigidas dos produtores. Embora o Pronaf estivesse sendo lançado com o objetivo explícito de democratizar o crédito, a questão das garantias não estava bem definida nas regras de concessão de financiamentos do Programa, e ficava para ser resolvida entre o agente financeiro e os tomadores de crédito. Se o Banco do Brasil, enquanto agente financeiro do Programa, resolvesse exigir a hipoteca do imóvel como garantia, a oportunidade estaria perdida. Por outro lado, certamente não era factível contar com empréstimos sem nenhuma garantia ou outro mecanismo de mitigação do risco. Alguma saída criativa deveria ser desenvolvida coletivamente.

\section{O jogo é de ganha-ganha. Mas como começá-lo?}

Após o lançamento do Pronaf pelo Governo Federal no final de junho, Milton Santana passou os primeiros dias de julho tentando achar um meio de qualificar seu município o mais rápido possível para beneficiar-se do programa. Estava claro para ele que o município possuía, em seu território, todos os atores sociais e políticos necessários para beneficiar-se do Programa, mas era preciso articulá-los. O jogo poderia ser de ganha-ganha, no sentido de que não havia interesses conflitantes entre os agentes envolvidos: todos seriam beneficiados e ninguém sairia perdendo. Mas como organizar o jogo? Como dar o pontapé inicial?

\section{Discussão}

Na condição de prefeito do município de Poço Verde, o que você faria? Seria possível criar um projeto de desenvolvimento econômico local e atender os requisitos do Pronaf? De que forma?

\footnotetext{
${ }^{4}$ As Casas do Agricultor (às vezes também denominadas “do produtor”), bem como as empresas estaduais de extensão e os sindicatos de trabalhadores rurais, são instituições bastante tradicionais no setor agrícola brasileiro, e habitualmente estão presentes mesmo em municípios pequenos. O CMDR de Poço Verde, ainda que existisse formalmente, não vinha se reunindo na prática. Além disso, embora formado por representantes de diferentes segmentos da agricultura municipal, o Conselho se caracterizava por uma certa centralidade no prefeito. Era ele quem nomeava os membros, reduzindo a possibilidade de vozes dissonantes. Apesar dessa "prefeiturização" do Conselho, a partir deste evento ele passará a existir de fato, fortalecendo o tema do desenvolvimento rural na agenda de políticas do município.
} 